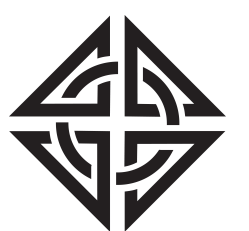

SCIENTIA
Sharif University of Technology

Scientia Iranica

Transactions A: Civil Engineering

http://scientiairanica.sharif.edu

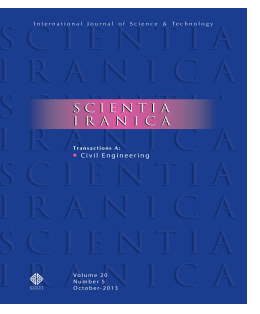

\title{
Determining the effect of ageing of nano-clay modified bitumen using atomic force microscopy
}

\author{
H.A. Omar ${ }^{a}$, M. Mubaraki ${ }^{\text {, N.H. Abdullah }}{ }^{\text {, A. Al-Sabaeei }}{ }^{\text {, A.M. Memon }}{ }^{\text {, }}$, \\ M. Imran Khand ${ }^{\text {, M.H. Sutanto }}{ }^{\text {, }}$, and N.I. Md Yusoff ${ }^{e, *}$ \\ a. Department of Civil Engineering, University of Tripoli, Elhei Eljamaiei 1, Elhei Eljamaiei Main Street, Tripoli, Libya. \\ b. Faculty of Engineering, Jazan University, Jazan 706, Kingdom of Saudi Arabia. \\ c. School of Housing, Building and Planning, Universiti Sains Malaysia, Penang, Malaysia. \\ d. Department of Civil and Environmental Engineering, Universiti Teknologi Petronas, Perak, Malaysia. \\ e. Department of Civil Engineering, Universiti Kebangsaan Malaysia, Selangor, Malaysia.
}

Received 18 June 2020; received in revised form 9 January 2021; accepted 17 April 2021

\section{KEYWORDS}

Bitumen;

Nano-clay;

Ageing;

Consistency tests;

Atomic force

microscopy.

\begin{abstract}
The present study aims to evaluate the effects of ageing simulation on the physical properties of Nano-Clay Modified Bitumens (NCMBs). Bitumen with the penetration grade of $60 / 70$ is modified with 0,2 , and $4 \%$ nano-clay, and the consistency of the samples is characterized using the penetration, softening point, and viscosity tests before and after aging. Atomic Force Microscopy (AFM) was employed to evaluate the surface roughness and tip deflection of the modified bitumens. The results of the consistency tests revealed that incorporation of nano-clay up to $4 \% \mathrm{NC}$ resulted in increased hardness of the modified bitumen, and all the modified bitumens were affected by ageing. Of note, the results from surface roughness and tip deflection showed a similar trend, while 2NCMB exhibited the lowest roughness and highest tip deflection. However, the results of the consistency tests and AFM conducted on ageing sensitivity of the bitumens were different, indicating that incorporation of nano-clay had an effect on the modified bitumen, but not on the unmodified bitumen. There was a high correlation between the results of consistency tests, surface roughness, and tip deflection, indicating that AFM could identify any changes in the fluidity of the bitumen. However, the correlation between the tip deflection and penetration was tenuous.
\end{abstract}

(C) 2021 Sharif University of Technology. All rights reserved.

\footnotetext{
*. Corresponding author. Tel.: +6038921 6447; Fax: +60389118344

doi: $10.24200 /$ sci.2021.56224.4610

\section{Introduction}

Bitumen, used primarily in civil engineering, is produced by distillation of crude oil. It is most frequently used as a binder in road construction, where the binder is combined with graded aggregate to obtain asphalt mixture [1]. Bitumen is very sensitive which is affected by sunlight and changes in temperature, moisture, oxygen, etc. This sensitivity can cause changes in the physical characteristics of the bitumen which are reflected in the mechanical properties of the asphalt mixture. Any weakness in the mechanical properties of bitumen can cause most problems occurring in 
pavements [2]. One of the properties of bitumen is ageing which, in turn, affects the mechanical properties of asphalt mixtures through certain mechanisms [3].

As a common mechanism observed in bitumen [4], oxidation occurs when diffused oxygen reacts with bitumen, especially in hot weather. The oxidation rate is for the most part determined by an increase in temperature, type of bitumen and its thickness, and type of aggregate and its gradation [5]. Such an increased oxidation rate of bitumen is the result of a dramatic increase in temperature during the mixing and compaction stages. This phenomenon is called short-term aging. The surface of a pavement is exposed to sunlight during its service life and the bitumen softens as the temperature increases, thus allowing oxygen to diffuse more readily inside the pavement structure. The diffusion and reaction of oxygen in bitumen resulted in increased viscosity which, in turn, increased its stiffness. Hence, cracking can be observed, especially in the low-temperature region [3].

Bitumen cannot stand for long-term heavy traffic and adverse weather conditions due to its natural properties [6]; however, modification is required to improve the properties of the bitumen [7]. One of the methods for bitumen modification is incorporation of additives such as polymer modifiers (elastomers, thermoplastic elastomers, and reactive polymers) that enhance its stiffness, elasticity, cohesion, and adhesion properties $[6,7$. As reported, bitumen is one of the multiphase composite materials on its mesoscale, whose mechanical properties, such as the elastic properties, directly affect the performance which is considered one of the important design parameters for achieving the desired practical performance $[8,9]$. It can be generally stated that modification of bitumen with additives has a direct effect on the physical, rheological, aging, and adhesion properties of the bitumen [10-12]. Recently, nano-materials have been added to the list of the additives that may be beneficial to bitumen and asphalt mixture [13]. This material has been proved to alter the physical properties of bitumen. Studies have confirmed the attenuation of the ageing effect of asphalt mixtures when nano-clay was added to the bitumen [14,15]. In these studies, several tests including consistency tests were conducted to investigate ageing, compactedmixture test, and chemical tests. The studies differ in terms of the materials used and applied wet condition. However, the results of all studies indicate that incorporation of nano-clay improve the properties of the bitumen and this improvement was reflected in the properties of the asphalt mixtures.

Recently, considerable attention has been devoted to using the Atomic Force Microscopy (AFM) technique to evaluate the properties of bituminous binders. The general information of material properties can be obtained using AFM such as surface topography image of the material and force-distance curve. In addition, different types of forces including mechanical contact force, friction, van der Waals force, capillary force, chemical bonding, and electrostatic and magnetic forces can be measured. The force-distance curve (or force curve) is employed to determine elasticity, hardness, Hamaker constant, adhesion, and surface charge densities [16]. AFM is a flexible high-resolution scanning probe microscopy technique that uses a lasertracked cantilever with a sharp underside tip to raster over the sample while interacting with the surface. The sample is scanned using a tip mounted on a cantilever spring, as illustrated in Figure 1. During scanning, the force between the tip and sample is measured by monitoring the deflection of the cantilever. A topographic image of the sample is produced by plotting the deflection of the cantilever against its position on the sample [16].

The contrast in the image is made due to the force between the tip and sample, which itself is the result of the separation of the tip from the sample as well as the material properties of both tip and sample. Therefore, the image contrast in the majority of applications is produced through a very short-range repulsion which occurs when the electron orbitals of the tip overlap with those of the sample (Born repulsion). Nonetheless, a more detailed interaction between the tip and sample can be used to determine the properties of the sample, tip, or medium between them. These measurements are referred to as "force measurements". In an AFM force measurement, the tip attached to a cantilever spring moves towards the sample in a normal direction. The vertical position of the tip and deflection of the cantilever are measured and transformed into forcedistance curves known as "force curves" [16].

AFM techniques have been recently used as a nano-scale test to investigate the general changes in

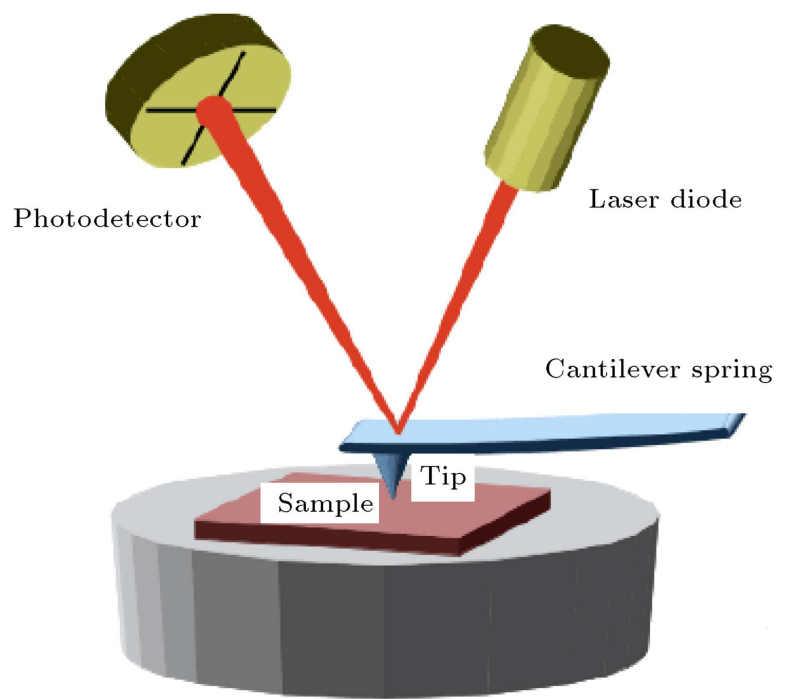

Figure 1. Schematic of an atomic force microscope [16]. 
bitumen due to the variations in its penetration grade, performance grade, modification, ageing, moisture damage, etc. [17-22]. In a study conducted by $\mathrm{Xu}$ et al. [23], to investigate the adhesive surface characteristics of bitumen, the micro-phase separated topographic morphologies were visualized by AFM, where topography, adhesion, and elastic modulus were measured. The investigation involved seven bitumen samples obtained from different suppliers. AFM is a very useful tool for characterizing the seven types of bitumens which have the same penetration grades, yet different structures with respect to their bee structure, Young's modulus, and adhesive forces [23]. Another study employed AFM to evaluate the effect of ageing on bitumen modified by organo-montmorillonite. The morphology of the bitumens was analyzed and compared with those of unmodified and organo-montmorillonite modified bitumens before and after ageing. The analysis of the results revealed the ability of AFM to characterize the modification of the bitumens and evaluate the effect of the ageing process [24].

This study aims to evaluate the effects of incorporating nano-clay to bitumen as well as the effect of ageing on the physical properties of the modified bitumens. Ageing procedures were conducted to simulate the effect of Short-Term Ageing (STA) and Long-Term Ageing (LTA) on the Nano-Clay Modified Bitumens (NCMBs). The ageing effects were then evaluated through consistency tests and then, AFM was employed to investigate surface topography and tip deflection. Statistical analysis was conducted to determine if there was a relationship between the results of the consistency tests and those of AFM. It was hypothesized that any variation in surface roughness and tip deflection measured by surface topography was correlated with the hardness of the material, meaning that while soft materials were characterized by high surface roughness, hard materials had low surface roughness.

\section{Experimental design}

\subsection{Materials and sample preparation}

The present study employed $60 / 70$ penetration grade bitumen with the penetration value of $69(0.1 \mathrm{~mm})$, softening point of $45\left({ }^{\circ} \mathrm{C}\right)$, and viscosity of 499 (mPa.s). The nano-clay used in this study is a halloysite nanotube composed of double layers of alumina, silicon, hydrogen, and oxygen with the chemical formula of $\mathrm{Al}_{4} \mathrm{Si}_{4} \mathrm{O}_{10}(\mathrm{OH})_{8} \cdot 4 \mathrm{H}_{2} \mathrm{O}$. The outer surfaces of the halloysite nano-tubes are characterized by electrochemical properties which are similar to those of silicon dioxide $\left(\mathrm{SiO}_{2}\right)$ with the negative charge at $\mathrm{pH} 6.5-$ 6.9 , as reported by the supplier. While silica is mainly located on the outer surface of the nano-tube, the positively charged alumina is located on its inner surface and edges [25]. The surface area of this kind of

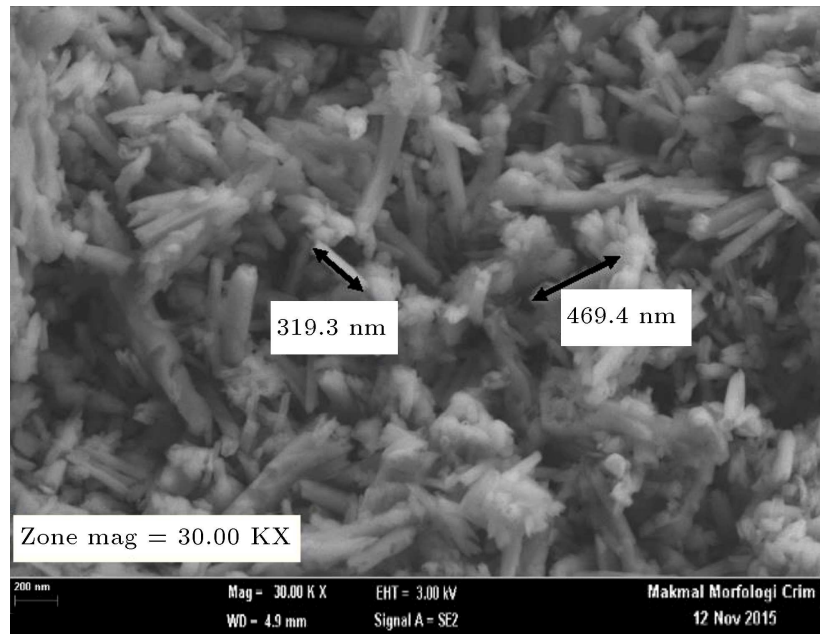

Figure 2. Field Emission Scanning Electron Microscopy (FESEM) for nano-clay particles.

nano-tube is approximately $57 \mathrm{~m}^{2} / \mathrm{g}[25,26]$. This nano tube has an outer diameter of $30-70 \mathrm{~nm}$ and a length between 200-600 nm [26,27]. Figure 2 displays an image of the nano-clay captured using a Field Emission Scanning Electron Microscope (FESEM).

The modified bitumen samples were prepared by adding different percentages of nano-clay, i.e., $0 \%, 2 \%$, $4 \%$, and $6 \%$, to the mass of bitumen. Bitumen in the amount of $200 \pm 10 \mathrm{~g}$ was poured into a can and heated to $150^{\circ} \mathrm{C}$ for one hour until reaching a fluid state. The additive was then heated at $100^{\circ} \mathrm{C}$ for four hours to remove all traces of moisture, and it was then gradually added to the liquid bitumen and mixed in a mechanical shear mixer at a rate of $500 \mathrm{rpm}$ until the additive particles were no longer visible. This process usually took between $3-5$ min. The rotational rate of mixing was then increased to $2000 \mathrm{rpm}$, and the mixing continued for another two hours. The selected mixing duration of two hours was to ensure a better storage stability of the modified bitumen, as recommended by Omar et al. [10]. For reference purpose, the sample with $0 \%$ nano-clay is called $0 \mathrm{NCMB}$, that with $2 \%$ nano-clay is $2 \mathrm{NCMB}$, that with $4 \%$ nano-clay is $4 \mathrm{NCMB}$, and that with $6 \%$ nano-clay is $6 \mathrm{NCMB}$.

\subsection{Ageing procedure}

The bitumens were first aged by Rolling Thin Film Oven Test (RTFOT) to simulate STA in accordance with the ASTM D2872 procedure. Modified bitumen in the amount of $35 \mathrm{~g}$ was poured into a standard glass bottle, after which the bottle was placed in the oven's carriage. The oven was kept at $163^{\circ} \mathrm{C}$ while the carriage rotates at a rate of $15 \mathrm{rpm}$ for $85 \mathrm{~min}$. Simulation of LTA was done using a Pressure Ageing Vessel (PAV) oven in accordance with the ASTM D6521 procedure. The LTA procedure was immediately performed after completing the STA simulation. Modified bitumen in 
the amount of $50 \mathrm{~g}$ was poured into a standard pan and placed in the PAV oven. The temperature was set at $109^{\circ} \mathrm{C}$ and the air pressure was $2.1 \pm 0.1 \mathrm{MPa}$. The ageing procedure was carried out for $20 \mathrm{~h}$.

\subsection{Consistency and storage stability tests}

Consistency tests were conducted to evaluate the physical properties of the unmodified and modified bitumens [28]. These test results were employed to determine any changes that might occur in the bitumen after modification and ageing procedures. In this study, the penetration and softening point tests were used to evaluate the changes to the physical properties of both unaged and aged bitumens. The penetration, softening point, and viscosity tests were conducted in accordance with ASTM D5, ASTM D36, and ASTM D4402, respectively.

Storage stability test was carried out in accordance with ASTM D7173-14 to determine the stability of a modified bitumen when stored at high temperatures. The hot modified bitumen was poured into an aluminum tube with a diameter of $25 \mathrm{~mm}$ and a length of $140 \mathrm{~mm}$; then, it was placed in a $163^{\circ} \mathrm{C}$ oven for 48 hours. The tube was allowed to cool; then, it was cut into three parts. The top and bottom sections of the tube were tested using the softening point test. To pass this test, the difference between the softening points of the two sections should be less than, or equal to, $2.5^{\circ} \mathrm{C}$. It should be noted that the percentage of the added nano-clay was determined based on the results of the storage stability test.

\subsection{Sample preparation for AFM testing}

The samples used in AFM testing must be very thin; hence, special attention should be drawn to obtain a thin and uniform surface. In this respect, Yu et al. [29] proposed two methods that could be used to prepare the samples: a) the solution-cast method and $b$ ) heat-cast method. In the first method, the bitumen is dissolved with toluene. The liquid bitumen is then placed on a glass slide and the excess bitumen is removed. This method, however, is not usually employed because of the possibility that the nano-clay particles absorb the toluene which cannot be easily removed. The second method uses heat-cast for such investigations. To prepare the unaged bitumen sample for the AFM test, a high temperature resistant tap was wrapped on each side of a glass slide, and the glass slide was then placed on a $150^{\circ} \mathrm{C}$ plate heater. The required temperature for the modified bitumens is $160^{\circ} \mathrm{C}$ in the case of STA and $170^{\circ} \mathrm{C}$ in the case of LTA to allow the sample to become more liquid. Next, a small drop of hot bitumen was taken from a $150^{\circ} \mathrm{C}$ oven and was placed on the glass slide, and the slide was immediately moved around to spread the bitumen and obtain a smooth thin surface. Next, any excess bitumen was removed. The taps were then removed from the glass slide and the sample was ready for AFM testing. The aforementioned procedures were applied, as described by Arifuzzaman [30].

\subsection{Atomic Force Microscopy (AFM)}

AFM was performed at Quasi-S Sdn Bhd Company, Singapore. AFM technique provides $2 \mathrm{D}$ and $3 \mathrm{D}$ profiles of the bitumen surface on a nano scale by measuring the forces between the sharp tip and bitumen surface. The contact, intermittent-contact, and non-contact modes can be used in this test depending on such factors as the type of material. However, the non-contact mode was used in this study since it was more suitable when dealing with soft materials such as bitumen. In the non-contact mode, the tip does not come into contact with the sample surface. The cantilever oscillates at or near its resonance frequency [31]. The AFM test, which uses a sharp tip to probe the surface features through raster scanning, can perfectly image the surface topography. The tip with a radius of 2 $\mathrm{nm}$ is supported on a flexible cantilever in the AFM machine. The AFM cantilever "gently" scans the surface and records the small frequency between the tip and bitumen surface. The deflection between the tip and bitumen surface depends on the spring constant (stiffness of the cantilever as well as the distance between the tip and bitumen surface). To measure the tip deflection for the bitumen, a force distance curve was used to determine the interaction force between a cluster of atoms in the AFM cantilever tip and the sample surface.

In the test, the surface of an asphalt or aggregate sample was probed with a sharp tip located at the free end of the cantilever. The attractive or repulsive force between the tip and sample surface made the cantilever bend or deflect. A laser beam reflection measured the cantilever deflection as the tip was brought vertically close to the sample surface and then away from it. The tips used in this test were made of silicon nitride $\left(\mathrm{Si}_{3} \mathrm{~N}_{4}\right)$. These tips are high-resolution silicon AFM cantilevers; a tip known as NSG01 bare was used for topography while another tip, CSG01 bare, was used for force curve. The test was conducted in a noncontact mode. The scan rate of the test was $3 \mathrm{~Hz}$ with a scanning area of $50 \mu \mathrm{m} \times 50 \mu \mathrm{m}$ for all samples [30]. At the end of the test, the Image Analysis P9 program was employed to analyze the scanned area and the results of the surface topography and tip deflection were obtained.

\section{Results and discussion}

\subsection{Consistency tests}

The results of the consistency tests for nano-clay modified bitumen samples are given in Table 1. As expected, 
Table 1. Physical properties of the modified bitumen.

\begin{tabular}{|c|c|c|c|c|c|c|}
\hline Test & Ageing stage & Standard test & ONCMB & 2NCMB & 4NCMB & 6NCMB \\
\hline \multirow{3}{*}{ Penetration $(0.1 \mathrm{~mm})$ at $25^{\circ} \mathrm{C}$} & Unaged & \multirow{3}{*}{ ASTM D 5} & 66 & 37 & 28 & 31 \\
\hline & $\mathrm{STA}^{\mathrm{a}}$ & & 57 & 34 & 26 & - \\
\hline & $\mathrm{LTA}^{\mathrm{b}}$ & & 34 & 29 & 23 & - \\
\hline \multirow{3}{*}{ Softening point $\left({ }^{\circ} \mathrm{C}\right)$} & Unaged & \multirow{3}{*}{ ASTM D36 } & 47 & 55 & 59 & 58 \\
\hline & STA & & 52 & 58 & 62 & - \\
\hline & LTA & & 60 & 62 & 64 & - \\
\hline \multirow{3}{*}{ Viscosity (mPa.s) at $135^{\circ} \mathrm{C}$} & Unaged & \multirow{3}{*}{ ASTM D4402 } & 551 & 705 & 775 & 732 \\
\hline & STA & & 794 & 821 & 906 & - \\
\hline & LTA & & 1123 & 915 & 1134 & - \\
\hline
\end{tabular}

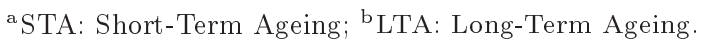

as the penetration value decreased, the values for softening point and viscosity increased, indicating that incorporation of the nano-clay increased the stiffness of the bitumen. Although incorporation of $6 \%$ nanoclay had a different effect on the bitumen, the results of the consistency tests were in good agreement in terms of any increase or decrease in the hardness of bitumen. This finding was in good agreement with those of previous studies $[32,33]$.

The results for bitumen storage stability are presented in Table 2. Good dispersion of nanoclay could enhance the storage stability of $2 \mathrm{NCMB}$ and 4NCMB; however, 6NCMB had better storage stability with a value greater than $2.5^{\circ} \mathrm{C}$, indicating that the agglomeration of particles is responsible for the enhanced storage stability. This demonstrates that the mixing speed should increase with the addition of higher percentages of NC. Based on the results of the storage stability test, $2 \mathrm{NCMB}$ and $4 \mathrm{NCMB}$ were chosen for this investigation.

Table 1 presents the results of the penetration, softening point, and viscosity tests for both the unaged and aged bitumens. The $6 \mathrm{NCMB}$ sample did not age since it was not included in the investigation. The results of the modified bitumen revealed that viscosity increased when nano-clay particles were added, and that viscosity continued to increase when the bitumens were subjected to ageing procedures. The following section discusses the evaluation of the modified bitumens.

Table 2. Results of storage stability test.

\begin{tabular}{cccc}
\hline Bitumen & $\begin{array}{c}\text { Top } \\
\left({ }^{\circ} \mathbf{C}\right)\end{array}$ & $\begin{array}{c}\text { Bottom } \\
\left({ }^{\circ} \mathbf{C}\right)\end{array}$ & $\begin{array}{c}\text { Different } \\
\left({ }^{\circ} \mathbf{C}\right)\end{array}$ \\
\hline $2 \mathrm{NCMB}$ & 53.4 & 55.3 & 1.9 \\
$4 \mathrm{NCMB}$ & 57.1 & 59.5 & 2.4 \\
$6 \mathrm{NCMB}$ & 56.3 & 60.0 & 3.7 \\
\hline
\end{tabular}

The ageing effect was evaluated using consistency tests, i.e., penetration, softening point, and viscosity tests. Table 1 presents the results of consistency tests for the unaged and aged bitumens. While subjecting the bitumens to STA and LTA resulted in increased viscosity of all bitumens, the rate of increase varied between the bitumens. For this reason, each test was evaluated to highlight the increase in viscosity and determine whether nano-clay could attenuate the ageing effects after each ageing stage.

An increase in hardness due to ageing was determined using the penetration test. The retained penetration was determined using Eq. (1):

$$
\text { Retained Penetration } \%=\left(\frac{P n_{\text {aged }}}{P e n_{\text {unaged }}}\right) 100 \text {, }
$$

where Pen aged is the penetration during the ageing stage and $\mathrm{Pen}_{\text {unaged }}$ the penetration for the unaged bitumen.

The effect of ageing was also evaluated using a softening point test. An increase in the rate of the ageing was determined using Eq. (2):

$$
\mathrm{SPR}=\left(\frac{\mathrm{SP}_{\text {aged }}-\mathrm{SP}_{\text {unaged }}}{\mathrm{SP}_{\text {unaged }}}\right) 100,
$$

where SPR is the Softening Point Ratio for STA or LTA, $\mathrm{SP}_{\text {aged }}$ the softening point of the bitumen in STA or LTA, and $\mathrm{SP}_{\text {unaged }}$ the softening point of the unaged bitumen.

Ageing effect was also investigated using viscosity test. The ageing index for the viscosity test was determined using Eq. (3):

$$
\text { Ageing Index }=\frac{\text { vis }}{\text { vised }_{\text {unaged }}},
$$

where visaged is the viscosity value after ageing, while vis $_{\text {unaged }}$ is the viscosity value for the unaged bitumen. 
Table 3. Physical properties of nano-clay modified bitumen after ageing.

\begin{tabular}{ccccccccc}
\hline & \multicolumn{2}{c}{ Retained penetration } & & \multicolumn{2}{c}{ SPR } & & \multicolumn{2}{c}{ Viscosity ageing index } \\
\cline { 2 - 3 } Sample & STA & LTA & & STA (\%) & LTA (\%) & & STA & LTA \\
\hline 0NCMB & 0.86 & 0.53 & & 13 & 30.4 & & 1.44 & 2.04 \\
2NCMB & 0.92 & 0.78 & & 5.5 & 9.1 & & 1.16 & 1.30 \\
4NCMB & 0.93 & 0.82 & & 5.1 & 8.5 & & 1.17 & 1.46 \\
\hline
\end{tabular}

The results from the retained penetration for the bitumens are listed in Table 3 . The results indicated that although all the modified bitumens were affected by ageing, there was a reduction in the ageing effect of both $2 \mathrm{NCMB}$ and $4 \mathrm{NCMB}$. Although an increase in the retained penetration for $2 \mathrm{NCMB}$ and $4 \mathrm{NCMB}$ after STA and LTA is an indication of reduced ageing sensitivity, 0NCMB was more affected. The values of SPR for the aged bitumens are listed in Table 3. The results indicate that the ageing ratio decreased for 2NCMB and 4NCMB and for both STA and LTA. This result was in good agreement with those of the retained penetration. Similar to the previous tests, the results of viscosity test revealed that the changes in the bitumen viscosity occurred due to ageing effects. The results in Table 3 show a lower ageing index for $2 \mathrm{NCMB}$ and $4 \mathrm{NCMB}$ than that for 0NCMB.

Incorporation of nano-clay resulted in reduced ageing sensitivity due to the unique heat absorption property of nanoclay [26,27]. Similar investigations proved that ageing resistance was enhanced by adding nano-materials [34-36]. This improvement in oxidation ageing resistance may be related to the unique feature of nano-clay, namely its heat absorption property $[26,27]$. The nano-clay particles were dispersed within the bitumen absorbing heat during the ageing process, thus attenuating the effect of oxidation. This attenuation of the ageing effect can be explained as follows: when bitumen is heated and mixed with nano-clay, some amounts of maltenes may enter the nano-tube; however, since the size of asphaltene is almost the same as the inner diameter of the tube, they are not able enter the nano-clay particles. An increase in the asphaltene content results in increased viscosity of the unaged modified bitumen. During the ageing process, the nano-clay particles protect the maltenes inside the tube structure and hence, they protect the bitumen against oxidation through the absorbing heat.

\subsection{Atomic Force Microscopy (AFM)}

AFM is a nano-scale test in which a structure is imaged by scanning the bitumen surface with a tiny tip $[31,37]$. In this section, AFM is employed to evaluate the effect of ageing simulation on the bitumen structure by measuring the surface roughness using topography imaging and determining tip deflection to identify the changes to the bitumen surface after exposing the bitumen to STA and LTA.

\subsubsection{Surface topography}

Surface topography images were taken for all the bitumens subject to STA and LTA simulations. Figure 3 shows the surface topography images for the unaged modified bitumens with a scanned area of $10 \mu \mathrm{m} \times 10 \mu \mathrm{m}$. The surface topography of all the bitumens was altered due to the effect of ageing. To determine the nature of this change on the surface, the surface roughness of all unaged and aged samples was evaluated. An area of $50 \mu \mathrm{m} \times 50 \mu \mathrm{m}$ was scanned to determine the surface topography of all the samples. The surface roughness is a parameter used for quantifying the surface texture of a sample. While a small roughness value indicates a smooth surface, a high roughness one indicates a rough surface [38].

Figure 4 shows a typical example of a bitumen surface obtained through topography imaging and a $2 \mathrm{D}$ roughness profile. The green line (the primary profile) shows the measured distance of the bitumen roughness

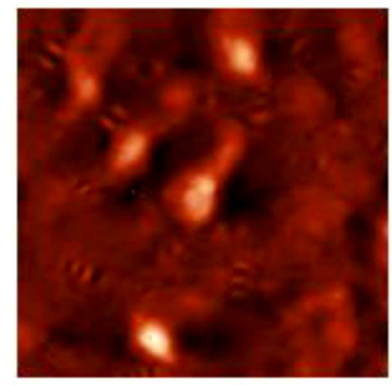

(a)

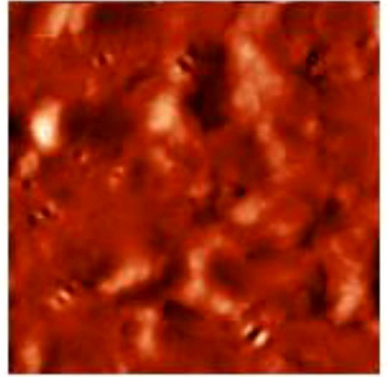

(b)

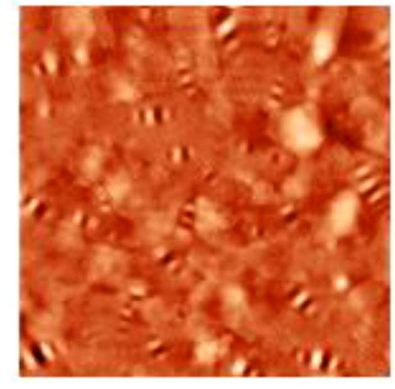

(c)

Figure 3. Surface topography before ageing for: (a) 0NCMB, (b) 2NCMB, and (c) 4NCMB. 


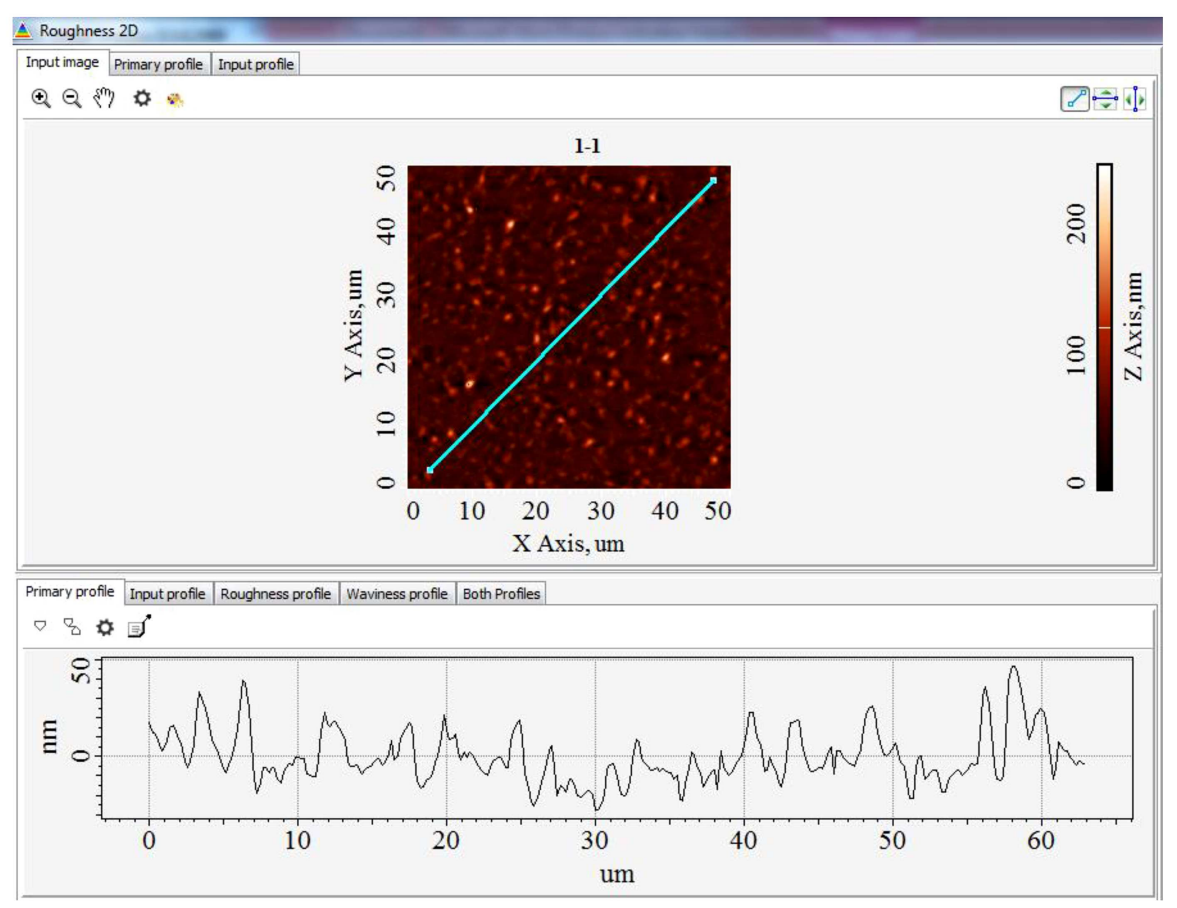

Figure 4. A typical example for the roughness of bitumen.

in Figure 3. The roughness of all the bitumens was measured before and after ageing. The values were recorded and analyzed using the Image Analysis P9 program to obtain the average roughness.

As mentioned earlier, while the high surface roughness of a soft bitumen is indicative of low viscosity (high fluidity), low surface roughness of hard bitumen is related to high viscosity (low fluidity) [38]. The three bitumen samples modified by nano-clay in the amount of 0,2 , and $4 \%$ bitumen masses were subject to the same mixing process. Any change in their surface roughness before STA would be a result of the dispersion of nano-clay particles. The results from the surface roughness of the modified bitumens are presented in Figure 5. Of note, incorporation of nano-clay particles to the bitumen resulted in reduced surface roughness of both $2 \mathrm{NCMB}$ and $4 \mathrm{NCMB}$. Therefore, it can be concluded that nano-clay has a considerable effect on the stiffness property of the modified bitumens. However, according to Figure 5, there is a slight increase in the surface roughness of $4 \mathrm{NCMB}$ compared to $2 \mathrm{NCMB}$, mainly because the incorporation of $4 \%$ nano-clay requires stronger mixing power to ensure a better dispersion of nano-clay in the bitumen. In other words, 2NCMB is slightly harder than 4NCMB. Further, the absorption of maltenes fraction by the nano-clay increased the asphaltene component of $2 \mathrm{NCMB}$.

STA also reduced the surface roughness of all the aged modified bitumens, hence an increase in the hardness of the bitumens. In order to evaluate the

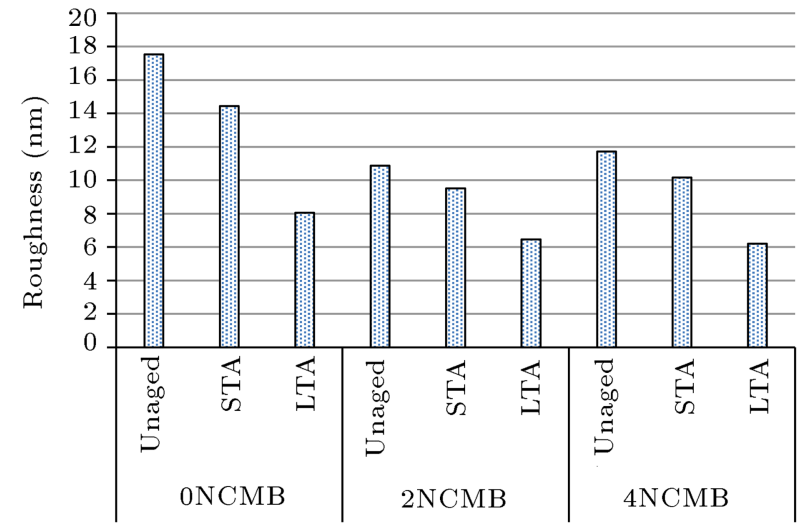

Figure 5. Results of surface roughness.

effect of STA on the modified bitumens and determine the difference in their response to the effect of STA, the ageing index was calculated using Eq. (3). The ageing index values of the surface roughness were $0.82,0.87$, and 0.87 for $0 \mathrm{NCMB}, 2 \mathrm{NCMB}$, and $4 \mathrm{NCMB}$, respectively (Table 4 ). It can be concluded that $0 \mathrm{NCMB}$ is more sensitive than $2 \mathrm{NCMB}$ and $4 \mathrm{NCMB}$. As already mentioned, nano-clay particles protect the maltenes inside the tube structure, hence enhanced hardness of the bitumens. In addition, the dispersed nano-clay particles protect the modified bitumen from oxidation by absorbing heat, thereby reducing its temperature sensitivity.

Subjecting the bitumen sample to LTA may result in lower surface roughness due to an increase in bitumen hardness. To evaluate the effect of LTA on the 
Table 4. Ageing index for surface roughness.

\begin{tabular}{ccc}
\hline Sample & STA & LTA \\
\hline 0NCMB & 0.82 & 0.46 \\
2NCMB & 0.87 & 0.60 \\
$4 \mathrm{NCMB}$ & 0.87 & 0.53 \\
\hline
\end{tabular}

modified bitumens and determine the difference in their response to that effect, the ageing index was calculated using Eq. (3), the results of which are presented in Table 4. According to this table, ONCMB is the most sensitive modified bitumen with an ageing index of 0.46 , indicating that the value of surface roughness was reduced by more than half of the surface roughness of the unaged bitumen. The ageing index values for $2 \mathrm{NCMB}$ and $4 \mathrm{NCMB}$ are 0.60 and 0.53 , respectively. Here, 2NCMB exhibited better resistance to LTA than 4NCMB, probably due to better dispersion of nanoclay particles in $2 \mathrm{NCMB}$; it may be the result of the agglomeration of nano-clay particles formed in the 4NCMB sample that reduces its ability to resist ageing. It is also possible that $4 \mathrm{NCMB}$ would require higher mixing power than the one used in this study.

\subsubsection{Tip deflection}

Tip deflection is a useful parameter that can be examined using the AFM technique. A force-distance curve was employed to determine the interaction force between a cluster of atoms at the AFM cantilever tip and sample surface [39]. This parameter can be obtained by determining the slope of the force-distance curve. An example of a typical force-distance curve is shown in Figure 6. In this test, the sample is probed through a sharp tip located at the free end of a cantilever. The attractive or retraction force between the tip and surface of the sample makes the cantilever bend or deflect. The attraction force was neglected to obtain the tip deflection value, as one of the objectives of this study. A laser beam reflection technique, built in

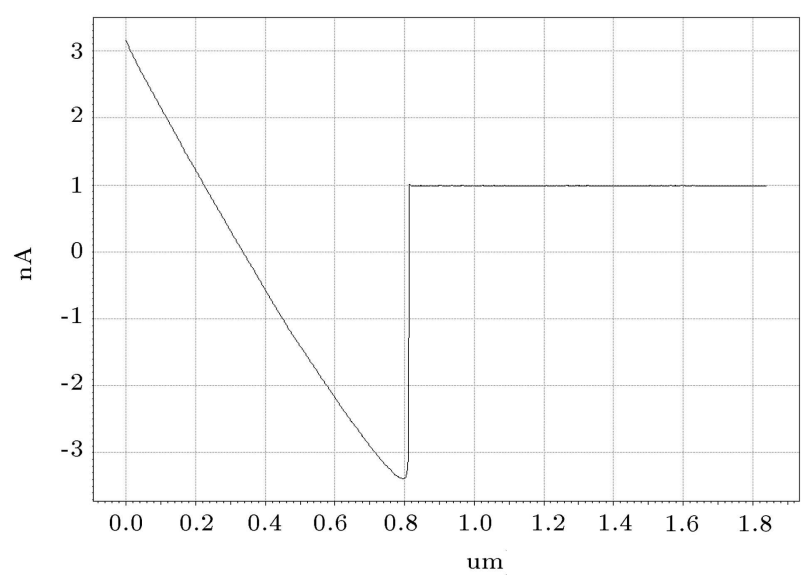

Figure 6. A force-distance curve for $2 \mathrm{NCMB}$ after Long-Term Ageing (LTA). the AFM system, measures the cantilever deflection as the tip is brought vertically close to the sample surface and, then, away from it. In Figure 6, the $y$ and $x$ axes represent the retraction force and the distance between the tip and the surface of bitumen, respectively.

The results of tip deflection on the bitumen surface generated by the program are presented in Figure 7 . The unaged and aged modified bitumens were evaluated using a silicon nitride tip, where tip deflection represents the solidity of the material. To be specific, harder materials produce low tip deflection values, while softer materials produce high tip deflection values [16].

According to Figure 7, incorporation of nanoclay particles to bitumen did not cause any change in 2NCMB; however, a reduction in the tip deflection of $4 \mathrm{NCMB}$ was observed, pointing to increase in the hardness of the binder. This result is totally different from that of the surface roughness. Therefore, it can be concluded that the addition of $2 \%$ nano-clay did not have any discernable effect on the bitumen while measuring the tip deflection. However, a slight reduction in the tip deflection of $4 \mathrm{NCMB}$, compared to that of $2 \mathrm{NCMB}$, may be attributed to the presence of $4 \%$ nano-clay which increases the hardness of the modified bitumen. According to the previous studies, although the AFM method was used to characterize a material, the results of force measurement varied and, in some cases, they did not correlate with each other [16].

STA can reduce the tip deflection of all the modified bitumens, as shown in Figure 6, which is indicative of the enhanced hardness of the modified bitumen. In order to evaluate the effect of STA on the modified bitumens and determine the difference in their response to that effect, the ageing index was calculated using Eq. (3). The ageing indices for tip deflection were calculated as $0.63,0.89$, and 0.89 for $0 \mathrm{NCMB}, 2 \mathrm{NCMB}$, and $4 \mathrm{NCMB}$, respectively (Table 5), indicating higher ageing sensitivity of $0 \mathrm{NCMB}$ than that of $2 \mathrm{NCMB}$ and 4NCMB. The LTA process was expected to increase the hardness of the aged bitumens while reducing the

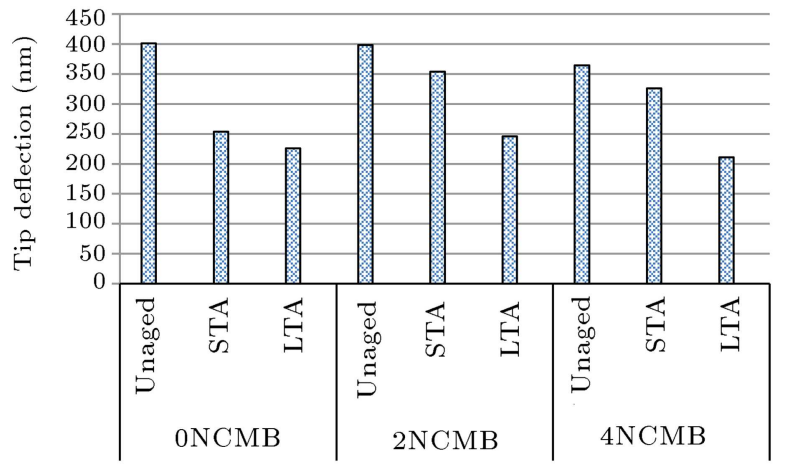

Figure 7. Tip deflection values for all samples. 
Table 5. Ageing index for tip deflection.

\begin{tabular}{ccc}
\hline Sample & STA & LTA \\
\hline 0NCMB & 0.63 & 0.56 \\
2NCMB & 0.89 & 0.62 \\
4NCMB & 0.89 & 0.58 \\
\hline
\end{tabular}

tip deflection. In order to evaluate the effect of LTA on the modified bitumens and determine the difference in their response to the effect of STA, the ageing index was calculated using Eq. (3). The obtained results revealed that $0 \mathrm{NCMB}$ was the most sensitive modified bitumen with an ageing index value of 0.56 ; in other words, the value of tip deflection was reduced to almost half of that of the tip deflection of the unaged bitumen. The ageing indices for $2 \mathrm{NCMB}$ and $4 \mathrm{NCMB}$ were 0.62 and 0.58 , respectively; therefore, it can be concluded that $2 \mathrm{NCMB}$ and $4 \mathrm{NCMB}$ exhibited better resistance to ageing in the LTA stage. As stated before, nano-clay particles protect the maltenes in the tube structure, thus increasing the hardness of the modified bitumen. The dispersed nano-clay protects the modified bitumen from oxidation by absorbing heat, thereby reducing its temperature sensitivity. However, the ageing index for tip deflection exhibited a similar trend to that of the ageing index for surface roughness. Both results confirmed that in terms of ageing resistance $2 \mathrm{NCMB}$ had the highest aging resistance, followed by $4 \mathrm{NCMB}$ and $0 \mathrm{NCMB}$.

\section{Correlation between consistency tests and AFM method}

This section presents the correlation between the results of the consistency tests and those of AFM method. This study hypothesized that any variation in surface roughness and tip deflection measured by surface topography was related to the hardness of the material. The Pearson product-moment correlation coefficient is a measure of the linear relationship between two different variables, taking a value between +1 and -1 [40].
While the value close to +1 indicates the strong linear proportional correlation between the dependent and independent variables, the value close to -1 indicates the strong inverse proportional correlation between the dependent and independent variables. The Pearson product-moment correlation coefficient is commonly used in engineering to measure the strength of the relationship between two variables and, in this study, it was used to investigate the correlation between the average results of consistency tests and those of the AFM method. The results are presented in Table 6. Based on the hypothesis associated with this coefficient, there is a good correlation between the surface roughness and the consistency test which ranged between -0.834 for the viscosity test and -0.927 for the softening point test. The negative sign indicates a decrease in one variable, namely surface roughness, while the softening point and viscosity exhibited an increase.

Tip deflection has a different correlation with the results of consistency tests compared to the correlation between surface roughness and consistency tests. The correlation ranges between 0.325 and -0.853 . The average result for tip deflection shows a correlation of 0.325 with the result for penetration, which is a poor relationship. The correlation with the result for softening point is -0.558 , and the strongest correlation of -0.853 is with the result for viscosity. The proposed hypothesis is in good agreement with the general results, indicating that there is a strong relationship between the results of consistency tests and those of the AFM test. This confirms that the AFM method is a useful tool for characterizing the modified bitumens and evaluating the ageing effect.

\section{Conclusion}

The present study aimed to evaluate the effect of ageing simulation on the modified bitumens. A bitumen with a penetration grade of $60 / 70$ was modified by nano-clay in the amounts of $0,2 \mathrm{~m}$ and $4 \%$ bitumen masses. The effects of Short-Term Ageing (STA) and

Table 6. Correlation between the results of consistency tests and Atomic Force Microscopy (AFM) method.

\begin{tabular}{|c|c|c|c|c|c|c|}
\hline \multicolumn{2}{|c|}{ Test } & $\begin{array}{c}\text { Surface } \\
\text { roughness } \\
\quad(\mathbf{n m})\end{array}$ & $\begin{array}{c}\text { Tip } \\
\text { deflection } \\
(\mathrm{nm}) \\
\end{array}$ & $\begin{array}{c}\text { Penetration } \\
(0.1 \mathrm{~mm})\end{array}$ & $\begin{array}{c}\text { Softening } \\
\text { point } \\
\left({ }^{\circ} \mathrm{C}\right)\end{array}$ & $\begin{array}{c}\text { Viscosity } \\
\text { (mPa.s) }\end{array}$ \\
\hline \multirow{3}{*}{ Surface roughness } & Pearson correlation & 1 & 0.612 & 0.875 & -0.927 & -0.834 \\
\hline & Sig. (2-tailed) & - & 0.080 & 0.002 & 0.000 & 0.005 \\
\hline & $\mathrm{N}$ & 9 & 9 & 9 & 9 & 9 \\
\hline \multirow{3}{*}{ Tip deflection } & Pearson correlation & 0.612 & 1 & 0.325 & -0.558 & -0.853 \\
\hline & Sig. (2-tailed) & 0.080 & - & 0.394 & 0.119 & 0.003 \\
\hline & $\mathrm{N}$ & 9 & 9 & 9 & 9 & 9 \\
\hline
\end{tabular}


Long-Term Ageing (LTA) were evaluated using the commonly used tests, i.e., penetration, softening point, and viscosity tests. Then, the surface roughness and tip deflection were determined using Atomic Force Microscopy (AFM). This paper hypothesized that in case the solidity of a material was determined by surface roughness and tip deflection, there would be a degree of reasonable correlation between the two parameters and consistency tests. The following concluding remarks were made based on the results obtained in this experimental study:

a) Incorporation of nano-clay to bitumen resulted in lower penetration and higher softening point and viscosity values. An increase in the hardness of $2 \mathrm{NCMB}$ and $4 \mathrm{NCMB}$ was greater than that of ONCMB. In addition, the results of storage stability pointed to the adequate stability of the modified bitumens with NC particles up to $4 \% \mathrm{NC}$;

b) The effects of STA and LTA were evaluated for all the modified bitumens with the consideration of the results obtained from the consistency test. However, the retained penetration, Softening Point Ratio (SPR), and viscosity ageing index were calculated to determine the sensitivity of bitumens to ageing. Both retained penetration and SPR values confirmed the best resistance of $4 \mathrm{NCMB}$ against ageing; however, the ageing index value for viscosity showed that $2 \mathrm{NCMB}$ had greater resistance against aging;

c) The results from surface roughness confirmed that incorporation of nano-clay particles would affect the solidity of $2 \mathrm{NCMB}$ and $4 \mathrm{NCMB}$. In addition, the hardness of $2 \mathrm{NCMB}$ was slightly higher than that of 4 NCMB. Further, the results of tip deflection test showed that while ONCMB and 2NCMB had the same tip deflection, 4NCMB had a smaller tip deflection, indicating that the hardness of $4 \mathrm{NCMB}$ increased;

d) The ageing indices for surface roughness and tip deflection were determined according to which 2NCMB and 4NCMB exhibited better resistance against ageing than $0 \mathrm{NCMB}$. However, in the case of LTA, 2NCMB was less affected than all the other samples;

e) The results obtained from the consistency tests proved that the addition of nano-clay particles delayed the ageing effect; this finding was supported by the AFM results, hence the enhanced ageing resistance;

f) Though in good agreement, the correlation between the results of consistency tests and AFM method varied, with the exception of the correlation between the tip deflection and penetration. To be specific, the changes identified by the results of consistency tests were also observed and confirmed by the results of AFM. Such a reduction in fluidity brought about by incorporating nano-clay as well as the effect of ageing simulation was already anticipated, as stated earlier in the hypothesis, thus confirming that AFM was a good tool for evaluating the ageing effect.

\section{Acknowledgement}

The authors would like to express their gratitude to Universiti Kebangsaan Malaysia for the financial support for this study (DIP-2020-003).

\section{References}

1. Yusoff, N.I.M., Shaw, M.T., and Airey, G.D. "Modelling the linear viscoelastic rheological properties of bituminous binders", Construction and Building $M a$ terials, 25, pp. 2171-2189 (2011).

2. Said, S.F. "Aging effect on mechanical characteristics of bituminous mixtures", Transportation Research Record, 1901(1), pp. 1-9 (2005).

3. Lu, X. and Isacsson, U. "Effect of ageing on bitumen chemistry and rheology", Construction and Building Materials, 16(1), pp. 15-22 (2002).

4. Petersen, J.C. "A review of the fundamentals of asphalt oxidation: chemical, physicochemical, physical property, and durability relationships", Transportation Research Circular, no. E-C140 (2009).

5. Petersen, J.C. and Harnsberger, P.M. "Asphalt aging: dual oxidation mechanism and its interrelationships with asphalt composition and oxidative age hardening", Transportation Research Record, 1638(1), pp. 47-55 (1998).

6. Pyshyev, S., Gunka, V., Grytsenko, Y., and Bratychak, M. "Polymer modified bitumen", Chemistry \& Chemical Technology, 10(4), pp. 631-636 (2016).

7. Al-Sabaeei, A., Yusoff, N.I.M., Napiah, M., and Sutanto, M. "A review of using natural rubber in the modification of bitumen and asphalt mixtures used for road construction", Jurnal Teknologi, 81(6), pp. 81-88 (2019).

8. Li, K.-Q., Li, D.-Q., Li, P.-T., and Liu, Y. "Mesomechanical investigations on the overall elastic properties of multi-phase construction materials using finite element method", Construction and Building Materials, 228, p. 116727 (2019).

9. Li, K.-Q., Li, D.-Q., and Liu, Y. "Meso-scale investigations on the effective thermal conductivity of multiphase materials using the finite element method", International Journal of Heat and Mass Transfer, 151, p. 119383 (2020).

10. Omar, H.A., Yusoff, N.I.M., Sajuri, Z., Ceylan, H., Jakarni, F.M., and Ismail, A. "Determining the effects of aging on halloysite nano-tube modified binders through the pull-off test method", Construction and Building Materials, 126, pp. 245-252 (2016). 
11. Souliman, M.I., Hajj, E.Y., and Sebaaly, P.E. "Impact of antistrip additives on the long-term aging rheological properties of asphalt binders", Journal of Materials in Civil Engineering, 27(8), p. C4014006 (2015).

12. Omar, H.A., Yusoff, N.I.M., Ceylan, H., Sajuri, Z., Jakarni, F.M., and Ismail, A. "Investigation of the relationship between fluidity and adhesion strength of unmodified and modified bitumens using the pull-off test method", Construction and Building Materials, 122, pp. 140-148 (2016).

13. Kavussi, A. and Barghabany, P. "Investigating fatigue behavior of nanoclay and nano hydrated lime modified bitumen using LAS test", Journal of Materials in Civil Engineering, 28(3), p. 04015136 (2016).

14. Ahmed, I., Ahmad, N., Mehmood, I., Haq, I.U., Hassan, M., and Khan, M.U.A. "Applications of nanotechnology in transportation engineering", in Advanced Research on Nanotechnology for Civil Engineering Applications: IGI Global, pp. 180-207 (2016).

15. Iskender, E. "Evaluation of mechanical properties of nano-clay modified asphalt mixtures", Measurement, 93, pp. 359-371 (2016).

16. Butt, H.-J., Cappella, B., and Kappl, M. "Force measurements with the atomic force microscope: Technique, interpretation and applications", Surface Science Reports, 59, pp. 1-152 (2005).

17. Lyne, Å.L., Wallqvist, V., and Birgisson, B. "Adhesive surface characteristics of bitumen binders investigated by atomic force microscopy", Fuel, 113, pp. 248-256 (2013).

18. Bellitto, V., Atomic Force Microscopy: Imaging, Measuring and Manipulating Surfaces at the Atomic Scale, Rijeka, Croatia (2012).

19. Omar, H.A., Yusoff, N.I.M., Ceylan, H., Rahman, I.A., Sajuri, Z., Jakarni, F.M., Ismail, A. "Determining the water damage resistance of nano-clay modified bitumens using the indirect tensile strength and surface free energy methods", Construction and Building Materials, 167, pp. 391-402 (2018).

20. Hung, A.M., Goodwin, A., and Fini, E.H. "Effects of water exposure on bitumen surface microstructure", Construction and Building Materials, 135, pp. 682688 (2017)

21. Nazzal, M.D., Kaya, S., Gunay, T., and Ahmedzade, P. "Fundamental characterization of asphalt clay nanocomposites", Journal of Nanomechanics and Micromechanics, 3(1), pp. 1-8 (2013).

22. García, A., Aguiar-Moya, J.P., Salazar-Delgado, J., Baldi-Sevilla, A., and Loría-Salazar, L.G. "Methodology for estimating the modulus of elasticity of bitumen under different aging conditions by AFM", Road Materials and Pavement Design, 20(1), pp. S332-S346 (2019).
23. Xu, M., Yi, J., Feng, D., Huang, Y., and Wang, D. "Analysis of adhesive characteristics of asphalt based on atomic force microscopy and molecular dynamics simulation", ACS Applied Materials \& Interfaces, 8(19), pp. 12393-12403 (2016).

24. Dehouche, N., Kaci, M., and Mouillet, V. "The effects of mixing rate on morphology and physical properties of bitumen/organo-modified montmorillonite nanocomposites", Construction and Building Materials, 114, pp. 76-86 (2016).

25. Levis, S. and Deasy, P. "Characterisation of halloysite for use as a microtubular drug delivery system", International Journal of Pharmaceutics, 243, pp. 125134 (2002).

26. Lau, K.-T., Gu, C., and Hui, D. "A critical review on nanotube and nanotube/nanoclay related polymer composite materials", Composites Part B: Engineering, 37(6), pp. 425-436 (2006).

27. Thakur, V.K. and Thakur, M.K., Eco-Friendly Polymer Nanocomposites: Chemistry and Applications, Springer (2015).

28. Read, J., Whiteoak, D., and Hunter, R.N., The Shell Bitumen Handbook, Thomas Telford (2003).

29. Yu, X., Burnham, N.A., Mallick, R.B., and Tao, M. "A systematic AFM-based method to measure adhesion differences between micron-sized domains in asphalt binders", Fuel, 113, pp. 443-447 (2013).

30. Arifuzzaman, M., Nano-Scale Evaluation of Moisture Damage in Asphalt, University of New Mexico, Albuquerque, New Mexico (2011).

31. Yu, X., Burnham, N.A., and Tao, M. "Surface microstructure of bitumen characterized by atomic force microscopy", Advances in Colloid and Interface Science, 218, pp. 17-33 (2015).

32. Fini, E.H., Hajikarimi, P., Rahi, M., and Moghadas Nejad, F. "Physiochemical, rheological, and oxidative aging characteristics of asphalt binder in the presence of mesoporous silica nanoparticles", Journal of Materials in Civil Engineering, 28(2), p. 04015133 (2016).

33. Alhamali, D.I., Wu, J., Liu, Q., Hassan, N.A., Yusoff, N.I.M., and Ali, S.I.A. "Physical and rheological characteristics of polymer modified bitumen with nanosilica particles", Arabian Journal for Science and Engineering, 41(4), pp. 1521-1530 (2016).

34. Zhang, H., Zhu, C., Yu, J., Shi, C., and Zhang, D. "Influence of surface modification on physical and ultraviolet aging resistance of bitumen containing inorganic nanoparticles", Construction and Building Materials, 98, pp. 735-740 (2015).

35. Abdullah, M.E., Zamhari, K.A., Hainin, M.R., Oluwasola, E.A., Hassan, N.A., and Yusoff, N.I.M. "Engineering properties of asphalt binders containing nanoclay and chemical warm-mix asphalt additives", Construction and Building Materials, 112, pp. 232240 (2016). 
36. Yusoff, N.I.M., Breem, A.A.S., Alattug, H.N., Hamim, A., and Ahmad, J. "The effects of moisture susceptibility and ageing conditions on nano-silica/polymermodified asphalt mixtures", Construction and Building Materials, 72, pp. 139-147 (2014).

37. Zhang, H., Wang, H., and Yu, J. "Effect of aging on morphology of organo-montmorillonite modified bitumen by atomic force microscopy", Journal of Microscopy, 242(1), pp. 37-45 (2011).

38. Santos, S. dos, Partl, M.N., and Poulikakos, L.D. "From virgin to recycled bitumen: A microstructural view", Composites Part B: Engineering, 80, pp. 177185 (2015).

39. Khatiwada, D. and Lamichhane, S.K. "A Brief overview of AFM force distance spectroscopy", $H i$ malayan Physics, 2, pp. 80-83 (2011).

40. Cohen, J., Cohen P., West, S.G., and Aiken, L.S., Applied Multiple Regression/Correlation Analysis for the Behavioral Sciences, Routledge (2013).

\section{Biographies}

Hend Ali Omar is a Senior Lecturer at the Department of Civil Engineering, University of Tripoli, Libya. She obtained her PhD degree from the Universiti Kebangsaan Malaysia, Malaysia in 2017 and has published several articles in reputable journals. She is mainly engaged in the study on pavement materials, construction, design and rehabilitation, and road safety.

Muhammad Mubaraki (PHD) is a Professor at the Department of Civil Engineering, Jazan University, Saudi Arabia. He is an active administrator, working as the Dean of the College of Applied Industrial Technology (CAIT), GM of projects, Chair of Department of Civil Engineering, and the Coordinator for training and collaboration units for college of engineering. His research focuses, on a large scale, on the Transportation Engineering, and he works on pavement engineering, including the pavement design, materials, construction, evaluation, maintenance, and management systems as well as assets management. His research also involves some topics in traffic engineering as well traffic characteristics and safety.

Noor Halizah Abdullah is a Lecturer at the School of Housing, Building, and Planning, Universiti Sains Malaysia. She received her BEng and MSc degrees in Civil Engineering and $\mathrm{PhD}$ degrees in Asphalt Technology from Universiti Sains Malaysia, Malaysia. Her research interests are asphalt technology, pavement materials, and highway engineering.

Abdulnaser Al-Sabaeei was born in Taiz, Yemen in 1983. He received his MSc degree in Highway and Transportation Engineering from Universiti Putra Malaysia, Selangor, Malaysia in 2017. He is currently a PhD scholar at Universiti Teknologi PETRONAS, Perak, Malaysia. He has worked as a Teaching Assistant at the Civil Engineering Department, Thamar University, Yemen, for seven years. His research interests include pavement materials, pavement design, and traffic engineering. He has also presented four papers in international conferences and published seven journal papers.

Abdul Muhaimin Memon was born in Hyderabad, Pakistan in 1995. He received his BSc degree from Mehran University of Engineering and Technology. Currently, he is pursuing MSc degree from Universiti Teknologi PETRONAS. His research interests include modeling of binder performance, bitumen modification, waste materials in bitumen, rheological, and morphological and chemical analyses of binders.

Muhammad Imran Khan was born in Pakistan in 1984. He received his BSc and MSc degrees in Civil Engineering from Pakistan. He is currently a PhD student at the Department of Civil and Environmental Engineering, Universiti Teknologi PETRONAS. He has also worked as a Lecturer for five years at King Faisal University, Saudi Arabia, where he was engaged in teaching and research activities. He published 16 papers in journals and five conference article papers. His research interests include asphalt modification, asphalt rheology, sustainable pavement materials, and semi-flexible pavements.

Muslich Hartadi Sutanto is a Senior Lecturer at the Civil and Environmental Engineering Department and Lead Coordinator of Sustainable Highway Nexus (SHiNe) within the Institute of Self-Sustainable Building, Universiti Teknologi PETRONAS. He holds a PhD degree from University of Nottingham, UK and Senior Professional Engineer qualification from The Institution of Engineers Indonesia. He has been a former advisor to the Institute of Road Engineering, Indonesian, Ministry of Public Works and a member of the board of experts in R\&D Agency, Indonesian Ministry of Transport.

Nur Izzi Md Yusoff (PhD) is an Associate Professor at the Department of Civil Engineering, Universiti Kebangsaan Malaysia, Malaysia. Currently, he is the Editor-in-Chief of Jurnal Kejuruteraan (Journal of Engineering) and a member of the editorial board in the International Journal of Pavement Research and Technology (IJRT) and Shock and Vibrations. His main research interests are pavement materials, construction, design, and rehabilitation as well as road safety. 